\title{
The Analysis of Wind Turbine Construction Safety System that Uses Vibroacoustic Diagnostics
}

\begin{abstract}
M. SzMECHTA*
Department of Electrical Engineering, Automatic Control and Informatics, Opole University of Technology Prószkowska 76, 45-758 Opole, Poland

The paper presents an analysis of the results of monitored on-line Enercon E40/6.44 wind turbine with gearless designed synchronous generator and a nominal power of $600 \mathrm{~kW}$. In recent months, this plant underwent with high frequency emergency stopped, the source of which was the acceleration control system located in the nacelle. This situation causes significant and unnecessary overload of the power plant components but most of all causes significant losses of production of renewable energy due to operational downtime. This article analyzes the circumstances of errors reported by the turbine control system associated with the acceleration sensor based on data recorded during several months of using on-line SCADA system. An assessment of the impact of a number of indicators related to the wind speed and direction of the nacelle on the operation of the safety system of the turbine has been carried out. Also the possible causes of irregularities were proposed, which may be the subject of further research, especially with the use of advanced diagnostics based on vibroacoustic method.
\end{abstract}

DOI: 10.12693/APhysPolA.124.574

PACS: $02.60 . \mathrm{Lj}$, 43.40.Le

\section{Introduction}

The basic components of a wind turbine safety system may include the following subsystems: automatic turbine stopping subsystem based on the hydraulic brake system, emergency battery powered blade angle control system (pitch control) and a set of measuring sensors. The group of sensors relevant to the safety and reliability of the turbine are: temperature sensors, current measurement systems of the powered devices, limit switches of rotary elements but also vibration and acceleration measurement systems placed in the nacelle. These factory-mounted sensors ensure mainly the safety of the mechanical construction of the whole turbine especially during periods of high wind [1].

The source of the historical data under analysis for purpose of this article was an on-line SCADA system, that meets the basic tasks in the field of data acquisition of power plant control system [2] and data transmission using widely available technology based on GSM/GPRS standards [3].

The results presented in this paper constitute a first research step of the analyzed turbine failures and their goal is to try to identify the circumstances of their occurrence. The next phase of the diagnostics should include advanced vibroacoustic methods with additional specialized equipment used in such works as [4-13] and advanced numerical data analysis techniques introduced in [14-16].

\section{Calculation of energy losses}

For the purposes of this article data archived in the SCADA system were exported and then have been sub-

*e-mail: m.szmechta@po.opole.pl jected to a suitable numerical analysis. The total number of measurement data points included 210676 measurements averaged over each measurement period corresponding to one minute.

Data length: $210676 \min =146$ days $=$ about 5 months.

The vector of measurement data consisted of the following values (related to $1 \mathrm{~min}$ ): minimal, mean, and maximal wind speed, mean rotor speed, minimal, mean, and maximal output power, acceleration error status (binary), wind and nacelle direction difference and nacelle position. In the period of 5 months the mentioned acceleration error occurred 104 times (Fig. 1).

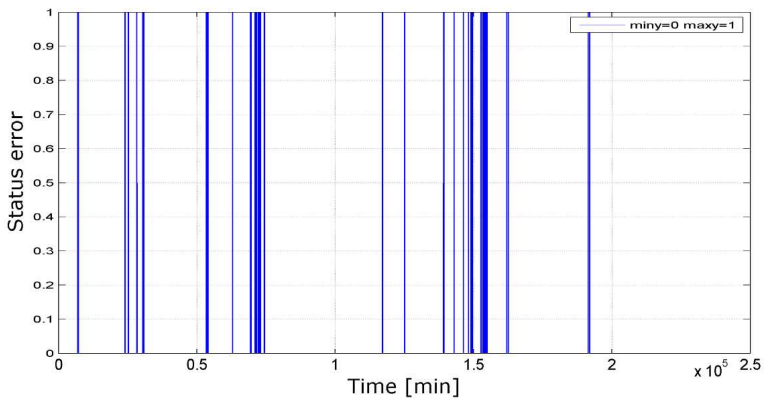

Fig. 1. Occurrences of acceleration error $($ value $=1$ ) in the whole analyzed data period encompassing above 210000 data points.

Total time of turbine error: $t_{\text {error }}=475 \mathrm{~min}=$ about $8 \mathrm{~h}$.

Total time of production losses: $t_{\mathrm{error} 2}=2126 \mathrm{~min}=$ $35.4 \mathrm{~h}$ (includes the time to restart the machine and normal power production state - Fig. 2).

At the maximal output power $\left(P_{\max }=600 \mathrm{~kW}\right)$ the energy losses were: $E_{\text {loss }}=21240 \mathrm{kWh}=21.2 \mathrm{MWh}$ 
$(\approx 20-40 \%$ of monthly production and $\approx 4-8 \%$ of total production in the whole analyzed period of time).

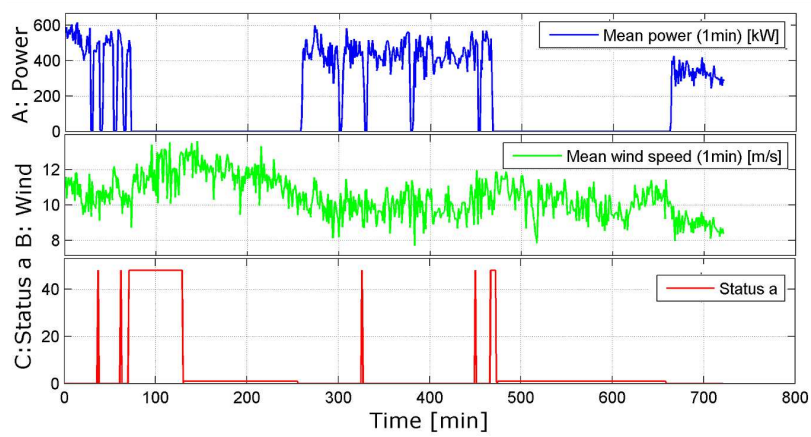

Fig. 2. The time chart of momentary generated power - A, wind speed - B and error signaling - C at selected moment.

Figure 2 magnifies the difference between the value of $t_{\text {error }}$ and $t_{\text {error2 }}$ indicators. It is clear that the signaling time of wind turbine failure is much shorter than the total downtime of the machine and thus does not represent all losses of electrical energy production as a consequence of its occurrence.

\section{The influence of several factors on the occurrence of vibroacoustic error}

The importance of the problem described in this article is indicated by the amount of energy losses including from 20 to $40 \%$ of the monthly production, which can reduce the long-term economic viability of the whole investment. It was found that the primary task of enabling the identification of the source of vibroacoustic fault signal reported by the wind plant control system is the analysis of the circumstances at the moment of its occurrence. In the following sections an attempt was made to analyze the circumstances through the impact of the following process variables available in the SCADA system: mean wind speed, nacelle position, mean rotor speed, mean output power, and wind and nacelle position difference. The analysis of one-minute minimum and maximum values for wind speed and momentary power production showed no significant difference in relation to the analysis of one-minute average, and therefore was abandoned completely in this article.

\subsection{The influence of mean wind speed on vibroacoustic error appearance}

The primary characteristic parameter of wind turbines is the momentary wind speed measured using an anemometer mounted at the nacelle. In the considered period of time, values in the range from 0 to $26 \mathrm{~m} / \mathrm{s}$ were observed.

Figure 3 plots a histogram of mean wind speed at which the error signal called by the accelerometer occurred. From the diagram it can be seen that the event

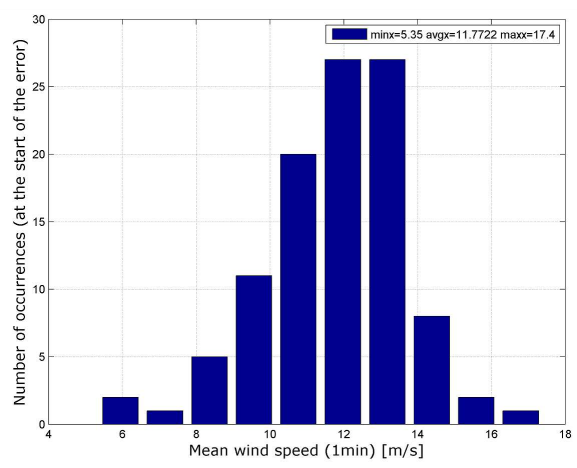

Fig. 3. The histogram of the mean wind speed at the time of an error reported by the accelerometer.

occurs mostly at wind speed of about $12 \mathrm{~m} / \mathrm{s}$ which may suggest problems with the own frequency resulting from the modification of the mechanical construction of the tower or even foundations, problems with the bearing of the generator or the nacelle itself and blades problems related with their calibration or parameterization of its control system.

\subsection{The influence of nacelle position on vibroacoustic error appearance}

Another characteristic parameter analyzed is the position of the nacelle, which is also an approximate indicator of the direction of the wind. These characteristic peaks can be seen in the histogram in Fig. 4.

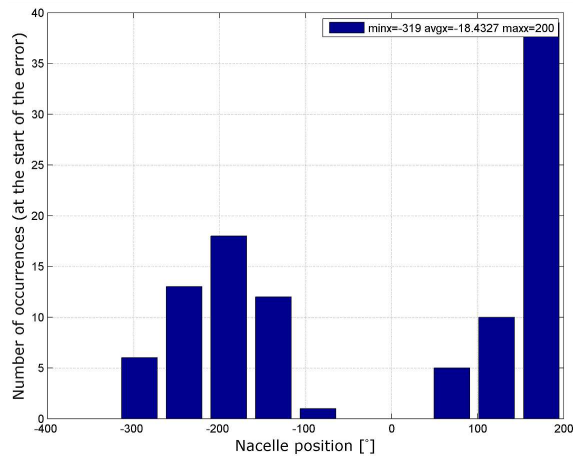

Fig. 4. The histogram of the nacelle position at the time of an error reported by the accelerometer.

\subsection{The influence of mean rotor speed on vibroacoustic error appearance}

Based on the histogram of mean rotor speed depicted in Fig. 5 it can be concluded that the errors always occur at the nominal rotor speed of about $32-33 \mathrm{rpm}$. Few values below are due to a sharp deceleration of the rotor and the impact of lower velocity values on one minute averaging of this parameter. In conjunction with the proposals for the wind speed at which it comes to emergency stop of wind turbine caused by the accelerometer there 
can be assumed that it comes to it during the phase of starting or ending phase of working pitch control system. These circumstances may indicate problems with the calibration parameters of the blades or some irregularities in the control and regulation system.

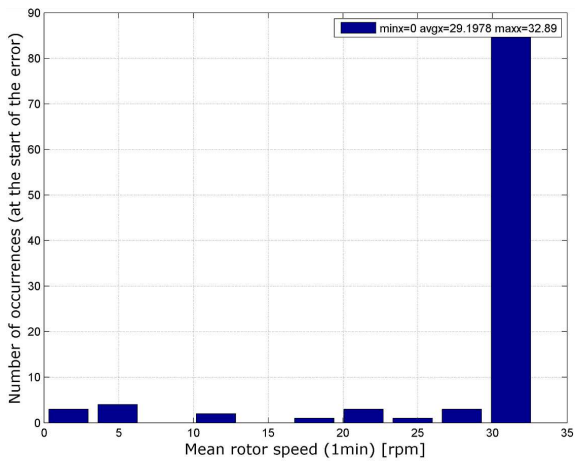

Fig. 5. The histogram of the mean rotor speed at the time of an error reported by the accelerometer.

\subsection{The influence of mean output power on vibroacoustic error appearance}

The results presented in Fig. 6 illustrate the full range of produced power from 0 to $630 \mathrm{~kW}$ according to the wind turbine controller factory settings. More precise results are showed in the histogram of average momentary power production at the moment of the fault indicator reported by the accelerometer included in Fig. 6. It is clearly visible that the emergency stop of wind turbine occurs mainly at power productions close to the nominal value of wind turbine. This situation is not directly related to the cause of irregularities, but is the direct cause of large losses of renewable energy which cannot be produced.

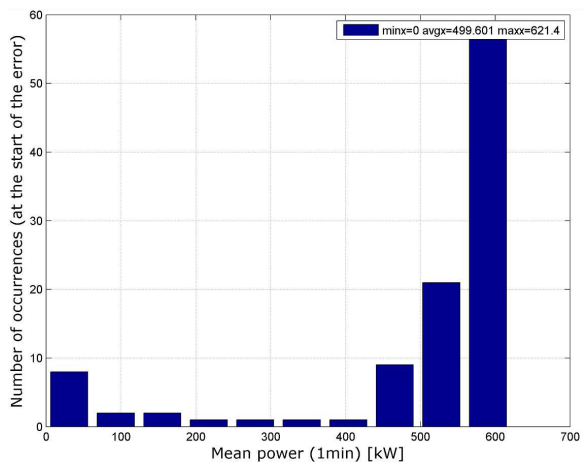

Fig. 6. The histogram of the mean generated power at the time of an error reported by the accelerometer.

\subsection{The influence of wind and nacelle position difference on vibroacoustic error appearance}

One of the main tasks of the wind turbine control system is to adjust the nacelle rotation direction to the direction of the wind velocity vector at a given time. The setup value of the controller is set to 0 , which means the overlapping of both operational directions, and the measured value is wind and nacelle position difference. Figure 7 shows the dependence of the error signal reported by the accelerometer in the nacelle, depending on the difference in wind and the nacelle direction at the time of its signaling through the construction safety system of the wind turbine. The drawing shows a certain asymmetry in the distribution of data points relative to the 0 value. This asymmetry is clearly visible on the histogram of the difference in wind and nacelle direction. Such a symptom may indicate irregularities in the bearing system of the generator, construction and calibration of the blades itself or incorrect parameterization of the pitch control system. This situation can also be further affected by strong one-sided lateral wind gusts occurring at the location of the wind turbine.

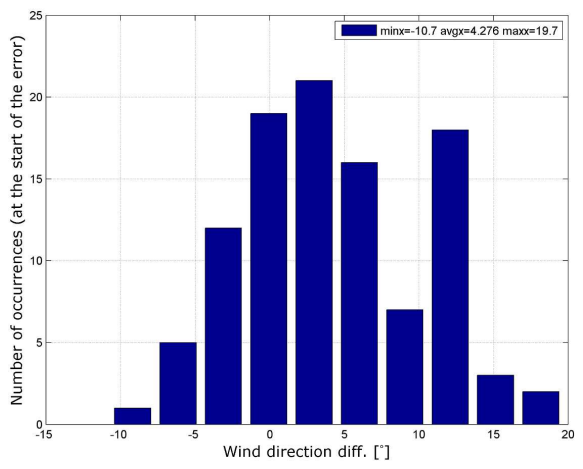

Fig. 7. The histogram of the wind and nacelle position difference at the time of an error reported by the accelerometer.

\section{Summary}

In conclusion, the analyses carried out using the process variables available in the SCADA system and averaged at one minute periods, such as: mean wind speed, nacelle position, mean rotor speed, mean output power, and wind and nacelle position difference, made it possible to define the circumstances under which it comes to fault signaling whose source is an accelerometer mounted in the nacelle of wind turbine. The circumstances of the error reported are as follows:

Wind speed:

- at mean wind speed $=11.7 \mathrm{~m} / \mathrm{s}$ errors occur very often,

- at mean speed $<9 \mathrm{~m} / \mathrm{s}$ and $>14 \mathrm{~m} / \mathrm{s}$ no error occurred.

Nacelle position:

- two dominant nacelle positions: $-200^{\circ}$ and $+190^{\circ}$.

Rotor speed: 
- at rotor speed $\geq 32 \mathrm{rpm}$.

Output power:

- at power production $>500 \mathrm{~kW}$.

Wind and nacelle direction:

- a clear asymmetry is visible on wind and nacelle direction difference.

Power curve:

- starting or ending of pitch system activity.

\section{Conclusion}

Error signaling reported by the supervisory and control system of wind power plant as a result of some irregularities is a key element of its safety system. The sources of signaling error may concern the electrical grid, defective elements and electrical components as well as a number of activities related to the normal operation of wind turbine such as twisted cables as a result of multiple rotation of the nacelle. But much of signaled errors are critical and are responsible for the stability and safety of mechanical construction of the wind turbine itself. It constitutes the safety of operations of any wind power plant.

The main object of the introduced analysis is the error signaling reported by the accelerometer located in the nacelle and its circumstances. The results presented in the paper do not allow to clearly identify the cause of the irregularities but they provide a very important diagnostic information and bring the diagnostic team much closer to the precise location of the source of the problem. Based on the collected data, we can predict the possible causes of their occurrence, which include: wrong calibration parameters or operation of blades, blade underweight, abnormal values of parameters of the wind turbine pitch control system, improper own vibration parameters resulting from the modification of the steel tower segment, possible problems with foundation, possible problems with the generator and azimuth bearing or whole azimuth itself.
The next steps require a need of further research, especially with the use of advanced diagnostics based on vibroacoustic method.

\section{References}

[1] E. Hau, Wind Turbines - Fundamentals. Technologies, Applications, Economics, Springer, Berlin 2005.

[2] M. Szmechta, M. Zmarzły, N. Adamkiewicz, Pomiary Automatyka Robotyka 12, 65 (2010) (in Polish).

[3] M. Szmechta, Pomiary Automatyka Robotyka 12, 53 (2010) (in Polish).

[4] S. Borucki, IEEE Trans. Power Deliv. 27, 670 (2012).

[5] A. Cichoń, S. Borucki, D. Wotzka, M. Szmajda, in: Acta Phys. Pol. A 122, 804 (2012).

[6] M. Szmechta, T. Boczar, P. Frącz, Acta Phys. Pol. A 120, 744 (2011).

[7] S. Borucki, Acta Phys. Pol. A 120, 571 (2011).

[8] K. Barczak, Bull. Pol. Acad. Sci., Techn. Sci. 59, 409 (2011).

[9] D. Wotzka, D. Zmarzły, T. Boczar, Acta Phys. Pol. A 118, 1272 (2010).

[10] D. Wotzka, A. Cichoń, T. Boczar, Arch. Acoust. 37, 19 (2012).

[11] D. Wotzka, T. Boczar, P. Frącz, Acta Phys. Pol. A 120, 767 (2011).

[12] S. Borucki, T. Boczar, A. Cichoń, Archiv. Acoust. 36, 49 (2011).

[13] T. Boczar, D. Zmarzły, J. Am. Soc. Nondestruct. Test. 62, 935 (2004).

[14] K. Gut, Bull. Pol. Acad. Sci., Techn. Sci. 59, 395 (2011).

[15] ] D. Wotzka, T. Boczar, D. Zmarzły, Acta Phys. Pol. A 116, 428 (2009).

[16] D. Zmarzły, IEEE Trans. Diel. Electr. Insulat. 16, $372(2009)$. 